\title{
USE THE DOE METHOD FOR TOOL DURABILITY INCREASE
}

doi: 10.2478/cqpi-2019-0075

Date of submission of the article to the Editor: 17/04/2019

Date of acceptance of the article by the Editor: 28/05/2019

\author{
L'uboslav Dulina ${ }^{1}$ - 0000-0002-5385-7476 \\ Eleonóra Bigošová ${ }^{1}$ - 0000-0002-3946-3614 \\ Miroslava Barbušová1 - 0000-0002-2654-1564 \\ Martin Gašo1 - 0000-0003-0926-2923 \\ Michala Šeligová1 - 0000-0003-0156-7845 \\ 1 University of Žilina, Slovakia
}

\begin{abstract}
Constantly improving, which is one of the principles of quality management is the base for good understanding, behaviour of individual processes, investigating variability and impact on its the process. The aim of every business is to increase profits. Reducing the cost of tools can also contribute to this. Utilising the DOE method to reduce the durability of removable cutting plate, as describe the article, is one of way, how to apply this method in practice. The DOE method enables find factors that are the most relevant to the production process and determine their best values. Using this method, you can set the selected inputs so that, the process achieves the desired results with maximum stability and resilience. The article contains a brief overview of Minitab software by which the collected process data was analysed. The core of the article describes how to solve the problem using the singular phases of the DMAIC cycle. Each of these phases has its own specific aim, which logically defines what activities each step is aimed at. DMAIC is extended variant of the process improvement model based at the Deming circle PDCA. Six sigma methodology is used as a standard procedure for project planning and realisation. At the end of an article is described that by increase durability of removable cutting plate the problems found in the analysis of the current condition that have been validated by a case study in the company have been eliminated.
\end{abstract}

Keywords: DOE, DMAIC, Durability, Removable cutting plate

\section{INTRODUCTION}

Experiments are used to improve ongoing processes or to innovate new processes or products. Planned experiments in manufacturing plants are performed as a series of tests. In practice, it is often necessary to solve tasks that lead to regression analysis. One of the methods to finding a suitable regression model is the DOE method. Using the DOE method to increase tool durability is one of the options to apply this method in practice. There is a large number of programs currently available for design of experiments. As a support tool for evaluating the collected process data, the expert team used the Minitab statistical software, which offers a wide range of quality control tools, and advanced statistical methods and design of experiments. 


\section{DEFINING A SOLVED PROBLEM}

The DOE method is currently used to test complex tasks where the results is a combination of many factors. This method is very effective and is used to reduce time and cost, design and test products or systems, or improve their quality. (Jankalová, 2018, Krajčovič, 2013 Zagorecki et al., 2013) From the point of view of practice, we have not been able to find the use of the DOE method to increase the durability of the removable cutting plate based on a literature review. We have tried to determine whether the DOE method can also be applied to this problem. We assume that by increasing the durability of the removable cutting plate with using the DOE method, $50 \%$ more products could be produced and increase the replacement interval by up to $100 \%$ over the current state. At the same time, a much higher cost savings on this tool would be achieved.

\section{DESIGN OF EXPERIMENTS (DOE)}

DOE is a systematic approach that allows you to find relationships between factors that affect a process or system. This method uses a scheduled series of ordered experiments that target these factors. A good experiment should consist of the minimum number of reps needed to get the information you need. Traditionally, experimentation has been implemented in laboratories, in industrial plants, or in agriculture. The DOE method is a summary of activities that can be divided into five stages on Fig. 1. (Ulewicz, 2018, Vaculiak et al., 2018)

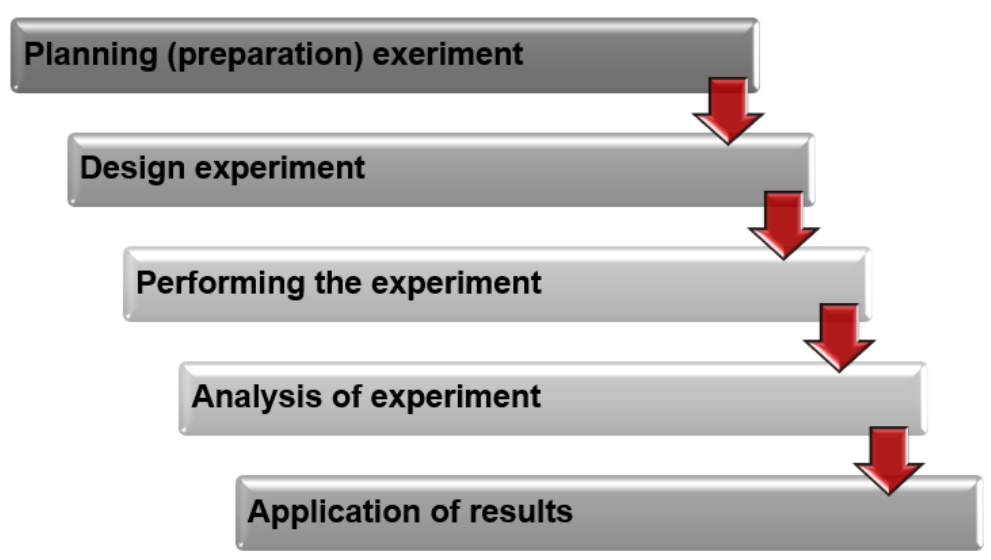

Fig. 1. Succession of the DOE method (Nenadál et al., 2008)

\section{APPLICATION OF THE DOE METHOD}

The aim of the research was to experimentally verify the applicability of the DOE method in increasing the durability of the removable cutting plate (Fig. 2). The company in which the research was executed is characterized by the production of bearing for cars and industry. This company is one of the European largest industrial enterprises. Research was executed in 2017. For the experiments, workplace of turning was selected, on which it was necessary to increased durability of the removable cutting plate because of the increased number of orders. Thereby would be achieved to increase number of pieces of work pieces at the same time and cost saving on this tool, as well. The workplace of turning, where the experiments were carried out, is characterised by the processing of the outer rings of the wheel bearings for the automotive industry. Before using the DOE method, durability of the removable cutting plate on the workplace of turning was 50 pieces of work pieces per cutting 
edge. The aim was to use the DOE method to achieve the durability of the removable cutting plate up to 100 pieces of work pieces per cutting edge, which will also represent the tool change interval.

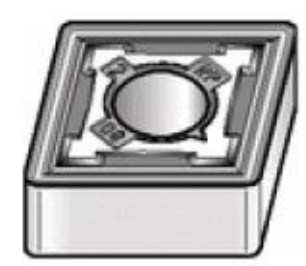

Fig. 2. Illustration of the shape of the removable cutting plate (Sasik et al., 2016)

A standard business document containing all phases of the DMAIC cycle, how it can see on Fig. 3, was used to design a durability of the removable cutting plate. This document is gradually supplemented by time course data that has been defined in the first phase of the DMAIC cycle.

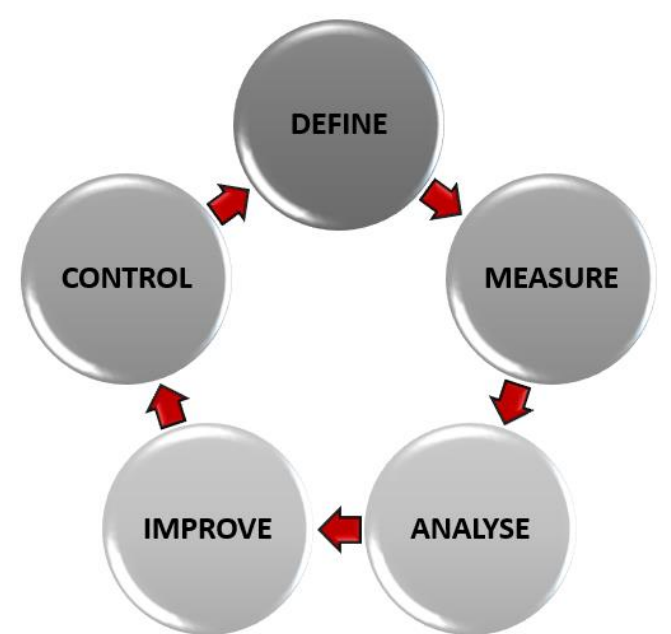

Fig. 3. The DMAIC cycle (Nenadál et al., 2008)

\subsection{Define}

The problem was defined in this phase. The aim of the project and the time range were determined. The aim of the project was increased the durability of the removable cutting plate on the workplace of turning. The biggest problems associated with the low durability of the removable cutting plate are:

- Machine produces less pieces;

- Increased tool costs;

- Increased downtime because of more frequent replacement of the removable cutting plate.

\subsection{Measure}

The measurement phase serves to evaluate the current state of durability of the removable cutting plate. The input data of durability of the removable cutting plate were collected by personal observation and recording. The expert team evaluated the current state with using the software Minitab. 


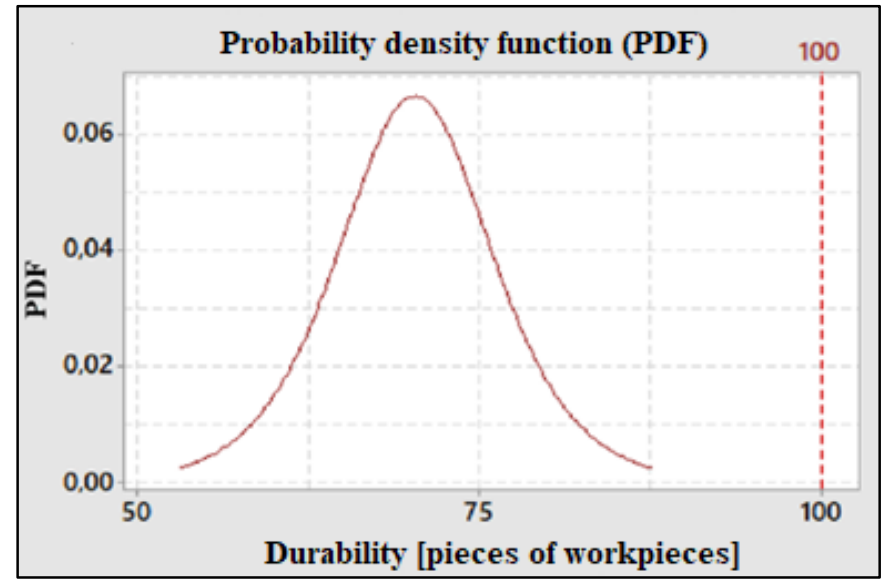

Fig. 4. Probability density function - current state (own research)

From the graph of Fig. 4 it can be see a 99,96\% probability that 100 pieces of workpieces per cutting edge will not be machined by any removable cutting plate. It follows that the aim 100 pieces of work pieces per cutting edge cannot be achieved. Although the aim will not be achieved, the experiment will continue because any increase of durability will have a positive impact on increasing the number of pieces of workpieces and ultimately on the overall cost savings of this tool, as well.

\begin{tabular}{|crrr|}
\hline \multicolumn{2}{|c|}{ Table of Cumulative Failure Probabilities } \\
& & \multicolumn{3}{c|}{$95 \%$ Normal Cl } \\
Time & Probability & Lower & Upper \\
\hline 100 & 0,999635 & 0,996534 & 0,999962 \\
\hline
\end{tabular}

Fig. 5. Probability before using the DOE method (own research)

\subsection{Analyse}

In this phase is important to find possible causes that create a problem. In Table 1 it can be see all parameters that affect the surface of work piece. Each parameter is one row of a turning program. Parameters limits are divided into three levels:

- Level -1 represents the lowest parameter limit;

- Level 0 represent the mean parameter limit;

- Level 1 represent the upper limit of the parameter.

Table 1

Limits of all parameters (own research)

\begin{tabular}{|l|c|c|c|}
\hline \multirow{2}{*}{\multicolumn{1}{|c|}{ Parameter }} & \multicolumn{3}{c|}{ Limits } \\
\cline { 2 - 4 } & \multicolumn{1}{|c|}{$\mathbf{0}$} & $\mathbf{1}$ \\
\hline Operating speed [m.min $\left.{ }^{-1}\right]$ & 960,00 & 0,00 & 980,00 \\
\hline N 140 [mm] & 0,30 & 0,37 & 0,45 \\
\hline N 260- N310 [mm] & 0,40 & 0,48 & 0,55 \\
\hline N 320 [mm] & 0,23 & 0,28 & 0,33 \\
\hline N 330- N 340 [mm] & 0,25 & 0,32 & 0,38 \\
\hline N 390 [mm] & 0,35 & 0,40 & 0,45 \\
\hline N 140 [mm] & 0,25 & 0,30 & 0,35 \\
\hline
\end{tabular}

The necessary experiments for this project were generated with using the Taguchi function (Fig. 6). After all the necessary settings, a table of 18 experiments with a 
different combination of factors was displayed. Subsequently, this table was supplemented by the monitored parameter, which is durability.

\begin{tabular}{|c|c|c|c|c|c|c|c|c|}
\hline & C1 & $\mathrm{C} 2$ & C3 & C4 & C5 & C6 & C7 & $\mathrm{C} 8$ \\
\hline & $\begin{array}{c}\text { Operating } \\
\text { Speed }\end{array}$ & N140 & N260-N310 & N 320 & N330-N340 & N390 & N410 & Durability \\
\hline 1 & 960,00 & 0,30 & 0,40 & 0,23 & 0,25 & 0,35 & 0,25 & 85,00 \\
\hline 2 & 960,00 & 0,30 & 0,48 & 0,28 & 0,32 & 0,40 & 0,30 & 93,00 \\
\hline 3 & 960,00 & 0,30 & 0,55 & 0,33 & 0,38 & 0,45 & 0,35 & 100,00 \\
\hline 4 & 960,00 & 0,37 & 0,40 & 0,23 & 0,32 & 0,40 & 0,35 & 90,00 \\
\hline 5 & 960,00 & 0,37 & 0,48 & 0,28 & 0,38 & 0,45 & 0,25 & 95,00 \\
\hline 6 & 960,00 & 0,37 & 0,55 & 0,33 & 0,25 & 0,35 & 0,30 & 97,00 \\
\hline 7 & 960,00 & 0,45 & 0,40 & 0,28 & 0,25 & 0,45 & 0,30 & 91,00 \\
\hline 8 & 960,00 & 0,45 & 0,48 & 0,33 & 0,32 & 0,35 & 0,35 & 96,00 \\
\hline 9 & 960,00 & 0,45 & 0,55 & 0,23 & 0,38 & 0,40 & 0,25 & 93,00 \\
\hline 10 & 980,00 & 0,30 & 0,40 & 0,33 & 0,38 & 0,40 & 0,30 & 96,00 \\
\hline 11 & 980,00 & 0,30 & 0,48 & 0,23 & 0,25 & 0,45 & 0,35 & 94,00 \\
\hline 12 & 980,00 & 0,30 & 0,55 & 0,28 & 0,32 & 0,35 & 0,25 & 100,00 \\
\hline 13 & 980,00 & 0,37 & 0,40 & 0,28 & 0,38 & 0,35 & 0,35 & 80,00 \\
\hline 14 & 980,00 & 0,37 & 0,48 & 0,33 & 0,25 & 0,40 & 0,25 & 73,00 \\
\hline 15 & 980,00 & 0,37 & 0,55 & 0,23 & 0,32 & 0,45 & 0,30 & 72,00 \\
\hline 16 & 980,00 & 0,45 & 0,40 & 0,33 & 0,32 & 0,45 & 0,25 & 80,00 \\
\hline 17 & 980,00 & 0,45 & 0,48 & 0,23 & 0,38 & 0,35 & 0,30 & 83,00 \\
\hline 18 & 980,00 & 0,45 & 0,55 & 0,80 & 0,25 & 0,40 & 0,35 & 81,00 \\
\hline
\end{tabular}

Fig. 6. Experiments with using Taguchi function (own research)

After collecting the durability data of the removable cutting plate, the effects of each parameter on its course were evaluated from all experiments. From the graph on Fig. 7 it can be see that the parameters operating speed and feed N140 (forehead machining) of the turning program have the great impact on durability. Parameters that have the greatest impact on the course of durability were further worked on. Parameters that did not greatly affect the durability course, in this case the other feeds in the tuning program, were set on the machine as constants and no longer worked with them.

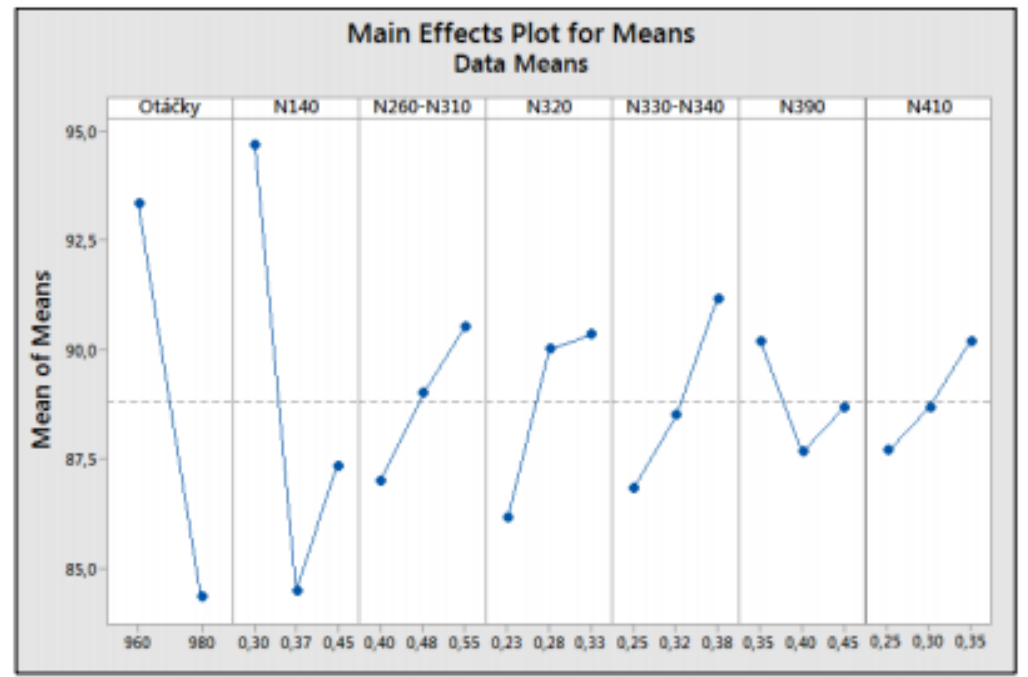

Fig. 7. Graphical analysis of the effects of individual factors (own research) 


\subsection{Improve}

In this phase, the best combination of parameters has been identified to get as close as it possible to the aim. From the graph on Fig. 8 for the operating speed and feed N140, the upper, middle and lower limits were determined. After determined these limits, a table with 9 experiments was generated using the Full Factorial function. Not only the durability but also the tact time of the machine was considered (columns C7 and C8).

\begin{tabular}{|l|l|l|l|l|}
\hline & \multicolumn{1}{|c|}{ C5 } & \multicolumn{1}{c|}{ C6 } & \multicolumn{1}{c|}{ C7 } & \multicolumn{1}{c|}{ C8 } \\
\hline & $\begin{array}{c}\text { Operating } \\
\text { Speed }\end{array}$ & \multicolumn{1}{|c|}{$\mathbf{N 1 4 0}$} & Durability & \multicolumn{1}{|c|}{ Tt } \\
\hline 1 & 930,00 & 0,30 & 73,00 & 40,30 \\
\hline 2 & 930,00 & 0,32 & 86,00 & 40,30 \\
\hline 3 & 930,00 & 0,34 & 90,00 & 40,20 \\
\hline 4 & 950,00 & 0,30 & 73,00 & 40,00 \\
\hline 5 & 950,00 & 0,32 & 100,00 & 39,70 \\
\hline 6 & 950,00 & 0,34 & 70,00 & 39,50 \\
\hline 7 & 970,00 & 0,30 & 77,00 & 39,20 \\
\hline 8 & 970,00 & 0,32 & 105,00 & 39,60 \\
\hline 9 & 970,00 & 0,34 & 100,00 & 39,50 \\
\hline
\end{tabular}

Fig. 8. Experiments with using Full Factorial (own research)

The Response Optimizer was used to determine the best combination of factors to achieve the highest durability of the removable cutting plate. On the Fig. 9 there are intervals of parameters (tact time of the machine and durability), in which these parameters could be moved. Tact time of the machine ranged from 38,957 $\mathrm{s}$ to $40,022 \mathrm{~s}$. The durability, which can achieve the removable cutting plate ranged from 79 to 131 pieces of workpieces, but the maximum values of this parameter can rarely be achieved.

\begin{tabular}{|lrr|c|c|}
\hline Response & Fit & SE Fit & $95 \% \mathrm{Cl}$ & $95 \% \mathrm{PI}$ \\
\hline $\mathrm{Tt}$ & 39,489 & 0,167 & $(38,957 ; 40,022)$ & $(38,599 ; 40,380)$ \\
Durability & 105,08 & 8,26 & $(78,79 ; 131,36)$ & $(61,10 ; 149,06)$ \\
\hline
\end{tabular}

Fig. 9. Interval of parameters operating speed and feed N140 (own research)

In this phase, the machine values of the parameters in Table 2 are set. The new exchange interval is always set as the smallest rounded $\mathrm{Cl}$ durability values. In this case, the new replacement interval was set to 80 pieces of workpieces per cutting edge. The newly set replacement interval has been tested in practice. The expert team, after using the DOE method with using Minitab software evaluated the collected data.

Table 2

Set parameter values after applying the DOE method (own research)

\begin{tabular}{|l|l|l|l|}
\hline & Row in the turning program & Method of verification & Set value \\
\hline 1 & Feed N260 $-\mathrm{N} 310[\mathrm{~mm}]$ & Taguchi & 0,55 \\
\hline 2 & Feed N320 [mm] & Taguchi & 0,33 \\
\hline 3 & Feed N330 $-\mathrm{N} 340[\mathrm{~mm}]$ & Taguchi & 0,38 \\
\hline 4 & Feed N390 [mm] & Taguchi & 0,35 \\
\hline 5 & Feed N410 [mm] & Taguchi & 0,35 \\
\hline
\end{tabular}




\begin{tabular}{|l|l|l|l|}
\hline 6 & Operating speed $\left[\mathrm{m}_{\mathrm{min}}{ }^{-1}\right]$ & Full Factorial & 970,00 \\
\hline 7 & Feed N140 [mm] & Full Factorial & 0,32 \\
\hline
\end{tabular}

The curve in the graph on Fig. 10 represent breaking of the removable cutting plate. After using the DOE method, it can be seen, that by adjusting the values affecting parameters to durability, exist the number of removable cutting plates that can machine 100 pieces of workpieces per cutting edge. At the same time, there is no number of removable cutting plates that would be machining less than 80 pieces of workpieces. By practical testing of the newly set replacement interval, it has been verified that 80 pieces of workpieces per cutting edge are the best values we can achieve in this process.

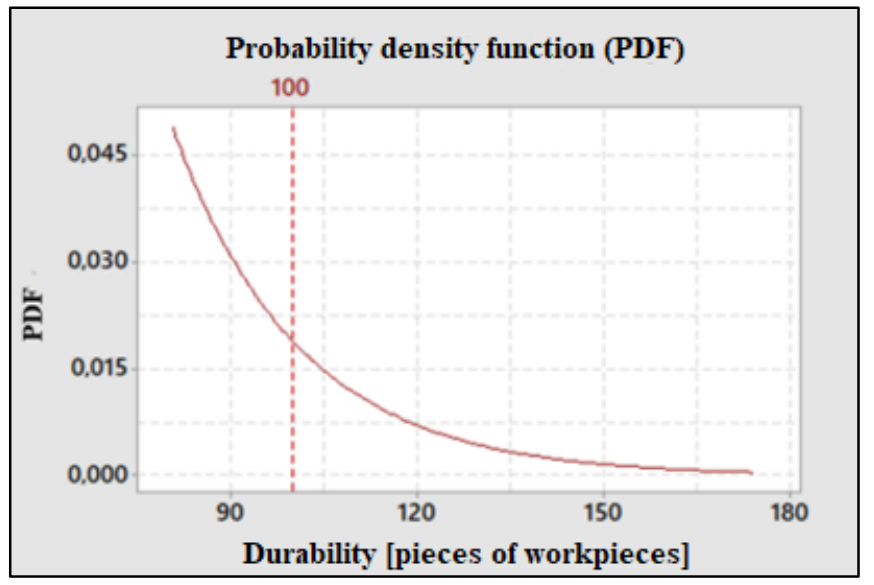

Fig. 10. Probability density function - improved state (own research)

\subsection{Control}

The aim of this phase is to ensure the sustainability of the solutions and to ensure that the improved process is maintained and monitored regularly. From the graph on Fig. 11 it can be seen the durability of the removable cutting plate before and after using the DOE method. With $20 \%$ tool damage, which admitted technologist, the number of machine pieces increased from 65 to 87 . After using the DOE method, the removable cutting plate could be adjusted from the original 50 pieces to 80 pieces of workpieces per cutting edge. Sustainability of the solution is ensured by regular control of the surface quality and dimensions of the machining pieces of workpieces.

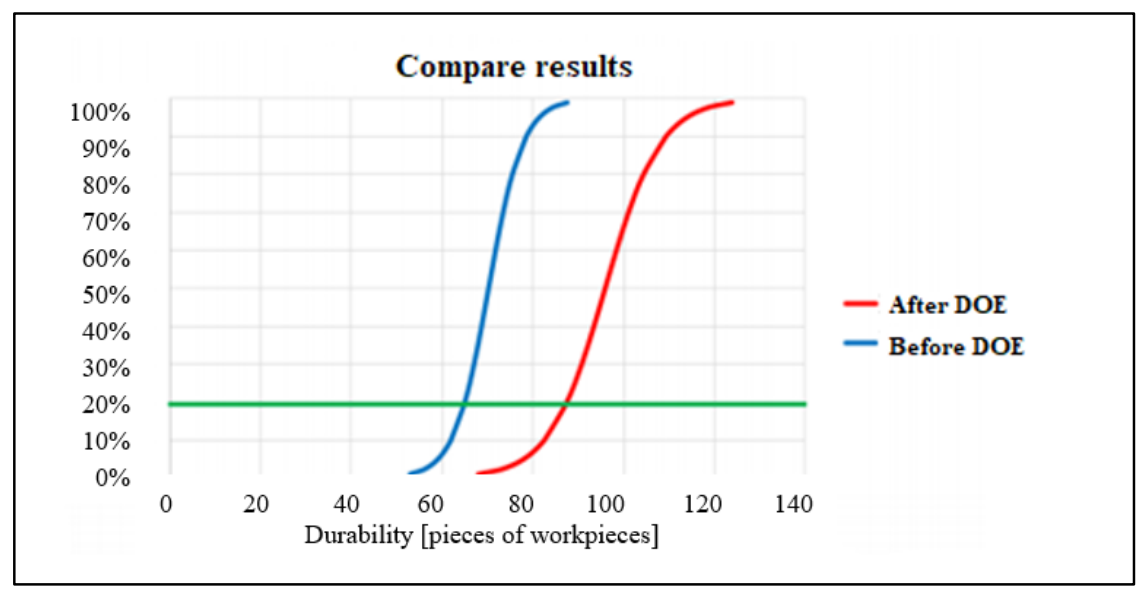

Fig. 11. Compare of the results (own research) 


\section{CONCLUSION}

The aim was to use the DOE method to find options for increasing the durability of the removable cutting plate. For the solution, a standard business document was used. This document consists of all phases of the DMAIC cycle. The assumed hypothesis was not fully proven by the expert team (by $50 \%$ more products produced per one removable cutting plate, by a $100 \%$ extended replacement interval of the removable cutting plate). Nevertheless, the experiment showed that by increasing the durability of the removable cutting plate, the production output increased by $33 \%$ (from 65 to 87 pieces). With $20 \%$ tool damage, which admitted technologist, the replacement interval increased by $60 \%$ (from 50 pieces to 80 pieces) workpieces per cutting edge. By increasing the durability of the tool, it has also achieved a significant overall cost savings per year for this tool. The DOE method was used only on one removable cutting plate and only in one process. However, it has been shown that experimentation can influence factors that affect the durability of the removable cutting plate and thus affect production output and costs of the tool. Based on achieved results, the authors will continue to experiment with other removable cutting plates in other processes and other workplaces, thus achieving much higher production outputs as well as reducing the tool costs.

\section{ACKNOWLEDGEMENTS}

This research was created with the support of the project: KEGA 022ŽU-4/2018

\section{REFERENCES}

Jankalová, M., 2014. Methodical basis of the Business Excellence status assessment. Second World Conference on Business. Economics and Management (BEM), Antalya, Turkey, Book Series: Procedia Social and Behavioral Sciences, 546-551.

Krajcovic, M., Plinta, D., 2013. Adaptive inventory control system for material items with continuous non-stationary demand. Management and Production Engineering Review, 5(1), 1-20. DOI: 10.2478/mper-2014-0002

Nenadál, J., Noskievicová, D., Petríková, R., Plura, J., Tosenovsky, J., 2008. Moderní management jakosti. Management Press, Praha. ISBN 978-80-7261-186-7

Sasik, R., Haluska, M., Madaj, R., Gregor, M., Grznar, P., 2016. Development of the Assembly Set for the Logistic Transport Solution. 55th International Conference of Machine Design Departments (ICMD), Prague, Czech Republic, Springer: Latest methods of construction design, 81-86.

Ulewicz, R., 2018. Outsorcing quality control in the automotive industry. MATEC Web of Conferences, 183, 03001, EDP Sciences.

Vaculik, J., Michalek, I., Kolarovszki, P., 2009. Principles of selection, implementation and utilization of RFID in supply chain management. Promet-Traffic \& Transportation, 21(1), 41-48.

Zagorecki, A. T. Johnson, D.E., Ristvej, J., 2013. Data mining and machine learning in the context of disaster and crisis management. International Journal of Emergency Management, 9(4), 351-365. 